This is not the version of record. The final verson - Wilcox, Christopher, Calvert, Anna, Metz, Jane, Kilich, Eliz, MacLeod, Rachael, Beadon, Kirsten, Heath, Paul, Khalil, Asma, Finn, Adam, Snape, Matthew, Vandrevala, Tushna, Nadarzynski, Tom, Coleman, Matthew and Jones, Christine (2019) Attitudes of pregnant women and healthcare professionals towards clinical trials and routine implementation of antenatal vaccination against respiratory syncytial virus : a multicenter questionnaire study. The Pediatric Infectious Disease Journal, 38(9), pp. 944-951. - can be found at https://dx.doi.org/10.1097/INF.0000000000002384 


\section{Attitudes of pregnant women and healthcare professionals towards clinical trials and routine implementation of antenatal vaccination against respiratory syncytial virus: a multi-centre questionnaire study}

Christopher R Wilcox MBBCh ${ }^{1}$, Anna Calvert MRCPH ${ }^{2}$, Jane Metz MBBS ${ }^{3}$, Eliz Kilich BM BCh ${ }^{2}$, Rachael MacLeod MBChB ${ }^{3}$, Kirsten Beadon BSc ${ }^{4}$, Paul T Heath MRCPH ${ }^{2}$, Asma Khalil MD ${ }^{5,6}$, Adam Finn PhD ${ }^{3}$, Matthew D Snape MD ${ }^{4}$, Tushna Vandrevala PhD ${ }^{7}$, Tom Nadarzynski PhD ${ }^{89}$, Matthew A Coleman MD ${ }^{10}$, Christine E Jones PhD ${ }^{11}$

1: NIHR Clinical Research Facility, University Hospital Southampton NHS Foundation Trust, Southampton, UK

2: Vaccine Institute, St George's, University of London, London, UK

3: Bristol Children's Vaccine Centre, University of Bristol, Bristol, UK

4: Oxford Vaccine Group, Department of Paediatrics, University of Oxford and the NIHR Oxford Biomedical Research Centre, Oxford, UK

5: Fetal Medicine Unit, Department of Obstetrics and Gynaecology, St George's University Hospitals NHS Foundation Trust, London, UK

6: Vascular Biology Research Centre, Molecular and Clinical Sciences Research Institute, St George's, University of London, London, UK

7: School of Social and Behavioural Sciences, Faculty of Business \& Social Sciences, Kingston University, Kingston, London, UK

8: Department of Psychology, University of Southampton, Southampton, UK

9: Department of Psychology, University of Westminster, London, UK

10: Department of Fetal Medicine, Princess Anne Hospital, University Hospital Southampton NHS Foundation Trust, Southampton, UK

11: Faculty of Medicine and Institute for Life Sciences, University of

Southampton and University Hospital Southampton NHS Foundation Trust, Southampton, UK

Abbreviated title

Attitudes to antenatal RSV vaccination: a questionnaire study

Running title

Attitudes to antenatal RSV vaccination 


\section{Corresponding author}

- Dr Christopher Wilcox

- NIHR Clinical Research Facility, Southampton Centre for Biomedical

Research, C Level West Wing, Mailpoint 218, Southampton General Hospital, Tremona Road, Southampton, S016 6DY

- Email: christopher.wilcox@soton.ac.uk

- Telephone: 02381204956

- Fax: 02381205023

Keywords: Vaccination; Pregnancy; Respiratory Syncytial Virus; RSV; Clinical Trials; Attitudes

\section{Conflict of Interests Statement}

$\mathrm{CW}, \mathrm{AC}, \mathrm{JM}, \mathrm{KB}, \mathrm{PH}, \mathrm{AK}, \mathrm{AF}, \mathrm{MS}$ and $\mathrm{CJ}$ are investigators for clinical trials done on behalf of their respective institutions, sponsored by various vaccine manufacturers, but receive no personal funding for these activities. 


\begin{abstract}
$\underline{\text { Abstract }}$

\section{Introduction}

Respiratory Syncytial Virus (RSV) is a common cause of infant hospitalisation and mortality. With multiple vaccines in development, we aimed to determine [1] the awareness of RSV amongst pregnant women and healthcare professionals (HCPs), and [2] attitudes towards clinical trials and routine implementation of antenatal RSV vaccination.
\end{abstract}

\title{
Methods
}

Separate questionnaires for pregnant women and HCPs were distributed within four hospitals in South England (July 2017-January 2018).

\section{Results}

Responses from 314 pregnant women and 204 HCPs (18\% obstetricians, 75\% midwives, 7\% unknown) were analyzed. Most pregnant women (88\%) and midwives (66\%) had no/very little awareness of RSV, unlike obstetricians (14\%). Amongst pregnant women, 29\% and 75\% would likely accept RSV vaccination as part of a trial, or if routinely-recommended, respectively. Younger women (16-24 years), those of 21-30 weeks' gestation, and with experience of RSV were significantly more likely to participate in trials (OR: 1.42 [1.72-9.86]; OR: 2.29 [1.22-4.31]; OR: 9.07 [1.62-50.86], respectively). White-British women and those of 21-30 weeks' gestation were more likely to accept routinelyrecommended vaccination (OR: 2.16 [1.07-4.13]; OR: 2.10 [1.07-4.13]). Obstetricians were more likely than midwives to support clinical trials ( $92 \%$ vs. $68 \%$, OR: $2.50,1.01-6.16)$ and routine RSV vaccination (89\% vs. $79 \%$, OR: 4.08 , 1.53-9.81), as were those with prior knowledge of RSV, and who deemed it serious.

\section{Conclusion}

RSV awareness is low amongst pregnant women and midwives. Education will be required to support successful implementation of routine antenatal 
vaccination. Research is needed to understand reasons for vaccine hesitancy amongst pregnant women and HCPs, particularly midwives. 


\section{Introduction}

Respiratory Syncytial Virus (RSV) is the leading viral cause of lower respiratory tract infection and bronchiolitis in infants, and is a major cause of hospitalization and mortality worldwide ${ }^{1}$. RSV infects more that $60 \%$ of children in their first year of life, and almost $100 \%$ by two years of age ${ }^{2}$. The estimated case fatality ratio for children hospitalized with severe RSV disease is $0.3 \%$ in industrialized countries, and $2.1 \%$ in developing countries ${ }^{3}$. Severe illness often occurs in children under six months ${ }^{4}$, particularly in those born prematurely or with underlying chronic illness, and the development of novel prevention and treatment strategies is an international priority 56 .

Antenatal vaccination is an effective means of protecting young infants from infection when the period of greatest susceptibility is shortly after birth ${ }^{7-10}$, and is now routinely recommended for use against a number of pathogens, including tetanus, influenza and pertussis ${ }^{11}$. No vaccine against RSV is yet approved for routine use, however a number of candidates are in development ${ }^{12} 13$, one of which is undergoing international phase III efficacy trials in pregnant women (NCT02624947) 11 14. An advantage of vaccination in pregnancy, rather than infancy, is that protection is afforded to infants from birth and extends through the period of highest risk of severe disease.

Achieving vaccine acceptance amongst pregnant women and maternity healthcare professionals (HCPs) has proven to be a considerable public health 
challenge, particularly in developed countries, and uptake of routine vaccination (especially influenza) remains suboptimal ${ }^{15}$. Furthermore, recruitment of pregnant women into clinical trials may be difficult, particularly as historically they have been excluded from participation, and there is a paucity of information regarding their recruitment and retention ${ }^{16} 17$. Pre-emptively ascertaining the level of awareness of RSV amongst pregnant women and HCPs, as well as their attitudes to vaccine clinical trials and routine implementation of an RSV vaccine, may allow us to identify interventions to optimise both recruitment for future trials and uptake in a routine setting.

Our aims were to determine [1] the level of awareness of RSV amongst pregnant women and HCPs, and [2] their attitudes towards clinical trials and routine implementation of RSV antenatal vaccination. 


\section{Methods}

\section{Questionnaire design and development}

Two separate anonymized questionnaires were developed for pregnant women and maternity HCPs (see supplementary information). These were developed with input from a multi-disciplinary study team including pediatricians, obstetricians, and health psychologists. Pregnant women and maternity HCPs were asked about their awareness and experience of RSV and bronchiolitis, pregnant women were asked whether they would hypothetically consider receiving an RSV vaccine as part of a clinical trial or if a vaccine were routinely recommended, and maternity HCPs if they would support clinical trials and routine recommendations. Women were also asked about the number of vaccines they would deem acceptable during pregnancy, and their opinions regarding the design of vaccine clinical trials. Part way through the questionnaire (having completed a self-assessment of their prior awareness/experience of RSV and bronchiolitis), participants were provided with written information on RSV and bronchiolitis inside a sealed envelope. This was done in order to inform further questions, whilst avoiding biasing their selfassessment in the previous section. Ethical approval was granted (reference 17/LO/0537) and the study was registered on ClinicalTrials.gov prior to recruitment (NCT03096574).

\section{Study population and recruitment}


The questionnaire for pregnant women was administered to women (aged $\geq 16$ years at the time of recruitment) attending for routine antenatal care at four study sites in southern England: University Hospital Southampton NHS Foundation Trust, Oxford University Hospitals NHS Foundation Trust, University Hospitals Bristol NHS Foundation Trust, and St George's University Hospitals NHS Foundation Trust, London. These four study sites were selected due to their high birth rates (all >4000 births/year ${ }^{18}$ ), and by distributing our questionnaire across four hospitals we attempted to increase the demographic diversity of our study population. The HCP questionnaire was administered to those working in either midwifery or obstetrics at the same four sites. Antenatal care for low-risk women in the UK is midwife-led, with women only seeing an obstetrician if they have a high-risk pregnancy, therefore the majority of potential respondents to our questionnaire were midwives.

Recruitment of participants took place from July 2017 to January 2018. Pregnant women were recruited in-person at antenatal clinics and wards by members of the study team on an opportunistic (non-sequential) basis over the recruitment period, and given paper questionnaires to complete. For recruitment of HCPs, all obstetricians and midwives at the participating institutions were identified by a senior member of staff not involved in the study (using email distribution lists). They were then contacted via an email containing a link to an online questionnaire, followed by two email reminders. Alternatively, HCPs may also have been recruited in-person by the study team (in a similar fashion to pregnant women), in which case they were also given paper questionnaires. At the time of recruitment, information provided on the nature of the questionnaire 
was kept to a minimum in order to avoid biasing participant responses. The participant information sheet stated only that the aim of the study was to better understand their attitudes towards RSV and vaccination during pregnancy. Participation in the study was voluntary and no financial or other incentive was offered. All participants gave informed consent.

\section{Questionnaire data analysis}

Questionnaire data were entered at the lead site (Southampton) into iSurvey (www.isurvey.soton.ac.uk). Statistical analysis was performed using IBM SPSS Statistics version 25. Ordinal regression analysis was performed, and adjusted odds ratios (ORs) and 95\% confidence intervals (CI) were calculated. P-values $<0.05$ were considered as statistically significant. Multicollinearity was examined using the tolerance test and the Variance Inflation Factor (VIF) to ensure variables with a VIF value exceeding 2.5 were not entered into the multivariate regression analysis. 


\section{Results}

A total of 525 participants completed the questionnaires: 321 pregnant women and 204 HCPs (18\% obstetricians, 75\% midwives, and for 7\% the professional role was unknown). Seven questionnaires from pregnant women, and five from HCPs, were excluded due to largely incomplete or illegible responses, leaving $513(98 \%)$ for analysis. The numbers of respondents were equally distributed between the four study sites. The full characteristics of respondents are displayed in Table 1.

\section{Responses from pregnant women}

Most pregnant women reported no (71\%) or very little (17\%) awareness of RSV, and reported no experience (93\%) [see Figure 1]. They were much more familiar with the term 'bronchiolitis' (only 14\% had never heard of it), and bronchiolitis tended to be perceived as more common and serious than RSV.

Of 312 who responded, 28\% were likely/very likely, 32\% not sure, and 40\% unlikely/very unlikely to consider receiving RSV vaccination as part of a clinical trial. The most important information to women was the likelihood of side effects for their baby (see Figure 2). Ordinal regression analysis (see Table 2) demonstrated that women were significantly more likely to accept RSV vaccination as part of a clinical trial if they had direct experience of RSV (OR: 9.07, 95\% CI: 1.62-50.86), were of younger age (16-24 years, OR: 1.42, 95\% CI: 1.72-9.86) and of 21-30 weeks' gestation (OR: 2.29, 95\% CI: 1.22-4.31). Women 
were significantly less likely to consider taking part if they perceived bronchiolitis as extremely/moderately serious (OR: $0.38,95 \%$ CI: $0.15-0.93$ ) or somewhat serious (OR: $0.27,95 \% \mathrm{CI}: 0.11-0.68)$.

More women would accept the vaccine if it was routinely recommended: of 308 who responded, $40 \%$ were very likely, $35 \%$ likely, $16 \%$ not sure, $5 \%$ unlikely and 4\% very unlikely. Women were significantly more likely to accept routine RSV vaccination if they identified as White British (OR: 2.16, 95\% CI: 1.22-3.83) versus non-White British, and were of 21-30 weeks' gestation (OR: 2.10, 95\% CI: $1.07-4.13)$

The most popular method of being approached regarding study involvement was face-to-face by their midwife (37\%), but $26 \%$ wouldn't have a preference (see Figure 3). The amount of time pregnant women would need to consider whether or not to participate in a trial was variable, but $72 \%$ responded $\leq$ one week $(17 \%$ $<24$ hours, $22 \%$ 1-2 days, 33\% 3-7 days, 18\% 2-3 weeks, and 10\% >1 month). For the majority (82\%), their decision to participate wouldn't be altered if the study was a randomised controlled trial, but $15 \%$ would be less likely to take part, and 3\% would be more likely. For $66 \%$, their decision wouldn't be altered if the study involved different doses of vaccine, but $31 \%$ would be less likely to take part, and 3\% would be more likely. The number of vaccines in pregnancy deemed acceptable by women was variable, however $25 \%$ would accept two vaccines or less, $27 \%$ would accept three, $11 \%$ four, $6 \%$ five, and $32 \%$ would accept more than five (i.e. as many as were recommended). Finally, in the freetext comments (see supplementary information), some women raised concerns 
regarding side-effects for their baby, and others stated support for vaccination, often describing personal experience.

\section{Responses from maternity healthcare professionals}

HCPs had greater awareness and experience of RSV than pregnant women, however obstetricians were significantly more familiar than midwives with both RSV (OR: 9.42, 95\% CI: 5.08-25.30, p<0.0001) and bronchiolitis (OR 2.68, 95\% CI: $1.29-5.55, \mathrm{p}=0.008$ ) [see Figure 1].

Of 192 HCPs who responded, 72\% were likely/very likely, 19\% not sure, and 9\% unlikely/very unlikely to support a clinical trial of RSV vaccination. The most important information to HCPs was the likelihood of side effects for the baby. Ordinal regression analysis (see Table 2) demonstrated that HCPs were significantly more likely to consider supporting a clinical trial if they were obstetricians (OR: 2.50, 95\% CI: 1.01-6.16), had good/some understanding of RSV (OR: 4.42, 95\% CI: 1.10-17.83), and perceived RSV as extremely (OR: 4.85, 95\% CI: 1.11-21.28) or moderately/somewhat serious (OR: 4.16, 95\% CI :1.2613.75). Likelihood of support also varied between study sites, with HCPs from sites A, B and C being significantly more likely to support a trial than those in site D.

More HCPs would support administration of the vaccine if it was routinely recommended: $47 \%$ definitely, $34 \%$ likely, $14 \%$ not sure, $4 \%$ unlikely and $0.5 \%$ very unlikely. Obstetricians were significantly more likely than midwives to support the administration of a routine RSV vaccine (OR: 4.08, 95\% CI: $1.53-$ 
9.81), as were those HCPs with good/some understanding of RSV (OR: 6.07, 95\%

CI: 1.23-29.93) and those who perceived RSV as moderately/somewhat serious

(OR: 4.41, 95\% CI: 1.32-14.78) [see Table 3]. Likelihood of supporting a routine RSV vaccine also varied significantly by study site with HCPs from sites A, B being significantly more likely to support routine vaccination than those in site D. Finally, in the free-text comments [see supplementary information] some HCPs reported concerns regarding the possibility of side-effects for the baby. 


\section{Discussion}

The high burden of RSV infection has driven recent efforts to develop an effective antenatal vaccine. This is a large multi-centre study in which we have attempted to establish the level of awareness of RSV, and attitudes to vaccine clinical trials and routine implementation of an RSV vaccine during pregnancy.

The awareness of RSV was low amongst pregnant women and midwives, compared with obstetricians. Younger pregnant women, those of 21-30 weeks' gestation, and those recalling direct experience of RSV, were significantly more likely to consider involvement in an RSV vaccine trial; and direct face-to-face interaction with a midwife was the preferred method of potential recruitment (amongst those who had a preference). Encouragingly, the majority of women would accept routine RSV vaccination, yet some (25\%) would still be unsure or unlikely to accept vaccination, particularly those of ethnic minorities, and onequarter would accept $\leq 2$ vaccines during pregnancy. Approximately $70 \%$ and $80 \%$ of HCPs would be likely to support an RSV vaccine trial and routine RSV vaccination respectively. Obstetricians were more likely than midwives to support both RSV trials and routine vaccination, as were those with prior knowledge of RSV and those who perceived it as a serious cause of infection. Support for potential RSV trials and routine vaccination also varied significantly by study site. 
It is notable that the awareness of RSV is so low given that RSV-associated respiratory tract infection is one of the commonest causes of infant hospitalisation and mortality worldwide ${ }^{1}$. Being thoroughly informed as to the indication and efficacy of vaccination has been shown to significantly increase the probability of its acceptance ${ }^{19} 20$. Therefore, with a number of RSV vaccine candidates currently in development, further education of both pregnant women and HCPs will be needed if we are to optimise engagement with vaccination trials and eventual uptake of RSV vaccines as part of routine care. Both pregnant women and HCPs seemed to better identify with the term bronchiolitis than RSV, and therefore specifically highlighting the link between these may be helpful in educational strategies. We do note that those who perceived bronchiolitis as serious were significantly less likely to consider participating in an RSV trial, however it is possible that this is a result of confounding due to a lack of knowledge regarding bronchiolitis. It is also interesting to note that women of 21-30 weeks' gestation were significantly more accepting of both RSV trials and routine vaccination, perhaps due to a sense of reassurance following their 20week anomaly scan and subsequent clinical review. Finally, the finding that women of ethnic minorities were less likely to accept routine RSV vaccination has been similarly observed in a number of previous studies of routinelyrecommended vaccines ${ }^{21-23}$, yet the underlying reasons remain poorly understood, and may include cultural/religious differences, as well as language barriers.

It is concerning that a number of the HCPs surveyed in this study would be unlikely to support either clinical trials or routine vaccination against RSV. 
Maternity HCPs can be strong advocates for antenatal vaccination, and encouragement from them (particularly midwives) may increase intention by up to 20 times $^{2425}$. Furthermore, HCPs are well-placed to facilitate clinical trial recruitment by identifying and speaking directly to eligible women, and addressing specific concerns about research safety and practicality ${ }^{17}$. It is important to note that obstetricians were significantly more willing to provide support for both clinical trials and routine vaccination than midwives, independent of their prior knowledge/experience of RSV or bronchiolitis. Barriers to engagement of midwives and nurses in research that have been identified in previous studies, include high workload, insufficient staff numbers and resources, a lack of confidence, and a lack of a research-supportive culture 26 27. Finally, the observed differences in support for both routine vaccination and clinical trials between study sites also suggests that there may be a potential risk of health inequalities based on differing recommendations across the South of England. All four sites had been involved in trials of antenatal vaccination (including RSV trials) prior to this study, and all have recently embedded vaccination into their routine antenatal care service. Site D only recently set up this vaccination service however (following the completion of this study), whereas it has been operating at the other sites for a longer period of time. They also report having comparatively less involvement from clinical teams in their vaccination trials. This may therefore, at least in part, explain the lower acceptance at this institution compared with sites A, B and C.

\section{Implications for clinical practice and research}


It is clear that education about RSV and bronchiolitis for pregnant women will be required in order to optimise uptake rates of antenatal RSV vaccination if it is introduced into routine care. Such education should highlight the safety and benefits of vaccination for their child, as studies have consistently shown that perception of potential harm to the baby is the primary reason for vaccine refusal 2528 , whereas messages emphasising the protective benefits conferred to infants is a major motivator for pregnant women to undergo vaccination ${ }^{29}$. As well as face-to-face counselling, possible strategies could include paper and online education resources 40 , as well as mobile phone text messages (such as Text4baby ${ }^{31}$ ) and smart phone apps (such as MatImms ${ }^{32}$ ). Education for HCPs on RSV and bronchiolitis will also be required in order to ensure active promotion of vaccination, and individual institutions should aim to tackle any general vaccine hesitancy within their own working body.

With regards to improving uptake into future antenatal vaccine trials, it is important to note that the majority of our respondents wouldn't be deterred by a randomized controlled trial design, and that direct face-to-face interaction with an HCP was the preferred method of recruitment. Improving study team outreach and forming integrated networks between research teams and healthcare providers/clinical staff may help improve clinicians' willingness to promote clinical studies to their patients, as well as pregnant women's willingness to join studies ${ }^{17}$, and this has proven a successful method of recruiting pregnant women in previous studies ${ }^{33} 34$. Social media and web-based recruitment may be used as a cost-effective supplement to traditional recruitment methods, and facilitate participation of traditionally harder-to-reach 
populations 17 35, however this approach may be less successful for higher-risk intervention-based studies, including antenatal vaccine trials.

Finally, it should be noted that there are other potential antenatal vaccines in development (including group B streptococcus and cytomegalovirus ${ }^{11}$ ), for which education and support from staff will also be required for successful implementation $^{22}$. Furthermore, it is also worth considering that whilst a third of our respondents would accept as many vaccines as were recommended, many women may be reluctant to accept high numbers of vaccines, especially if given on separate occasions ${ }^{36}$ 37. Pragmatic research is therefore required to consider the logistical aspects of future antenatal vaccine delivery.

\section{Strengths and limitations}

This study had significant numbers of respondents, and by distributing our questionnaire across four hospitals in southern England we attempted to maximise the diversity of our study population. That said, the responses to the questionnaire cannot be taken as representative of all pregnant women and maternity HCPs. Our respondents were all recruited from antenatal clinics based in tertiary hospitals, and therefore it is also possible that our sample was missing subsets of the population that tend to be more anti-vaccination. Future studies might benefit from recruiting over a wider geographical area, and from different types of sites (such as non-tertiary hospitals and primary care), and perhaps utilising online recruitment via pregnancy-associated websites and social media. It may have been also beneficial to collect socio-economic data from our participants in order to assess the representativeness of our study sample. Other 
limitations are that data on the uptake of antenatal vaccination was not collected from women's medical records following delivery, and data on the uptake of influenza vaccination amongst HCPs wasn't collected. Finally, the number of pregnant women/HCPs approached, and the number who declined participation (as well as their reasons for doing so) was not recorded, and we are therefore unable to report this data.

\section{Conclusions}

RSV awareness appears low amongst pregnant women and midwives in the UK. Education will be required to optimise engagement with vaccination trials and eventual uptake of RSV vaccination following routine implementation, with an emphasis on women of ethnic minorities. Active promotion of vaccination must be incorporated into routine antenatal care, and further research is needed to understand reasons for vaccine hesitancy amongst both pregnant women and HCPs, particularly midwives. 


\section{Figure captions [images to be reproduced in colour online only]:}

Figure 1: Reported familiarity and experience with RSV (A \& B) and bronchiolitis (C) amongst pregnant women, midwives and obstetricians, prior to their involvement in this study.

Figure 2: Information that would be considered most important to the pregnant women in this study when deciding whether to take part in a research study of an RSV vaccine (A), and other factors which would discourage them from taking part (B).

Figure 3: Preferred method of being approached regarding potential clinical trial involvement amongst the pregnant women in this study

\section{Acknowledgements}

The authors would also like to thank all the pregnant women and healthcare staff who took part in the questionnaire, Stephen Yekini for his assistance with data collection in Southampton, and all of the non-study staff that helped facilitate recruitment in the participating sites.

\section{Author Contributions}

CW drafted the manuscript and was principal investigator. All authors contributed to questionnaire design and critically revised the manuscript. $\mathrm{CW}$, AC, JM, EK, RM, KB, PH, AK, AF, MS, TV, TN, MC and CJ were involved in study set up and data collection at the participating sites. CW, TN and CJ performed the data analysis. CJ conceived the study and was chief investigator. All authors approved the final version of the manuscript.

\section{Conflict of Interests Statement}

$\mathrm{CW}, \mathrm{AC}, \mathrm{JM}, \mathrm{KB}, \mathrm{PH}, \mathrm{AK}, \mathrm{AF}, \mathrm{MS}$ and $\mathrm{CJ}$ are investigators for clinical trials done on behalf of their respective institutions, sponsored by various vaccine manufacturers, but receive no personal funding for these activities.

\section{Funding}

The study was supported by a grant from the British Paediatric Allergy Immunity and Infection Group (BPAIIG). BPAIIG had no role in the study design, data collection, data analysis/interpretation, report writing, or the decision to submit the manuscript for publication.

\section{Clinical trial registration}

The questionnaire study was registered on ClinicalTrials.gov prior to recruitment (NCT03096574).

\section{Ethical approval}

Ethical approval was granted from the West London \& GTAC NHS Research Ethics Committee (reference 17/LO/0537). 


\section{$\underline{\text { References }}$}

1. Hall CB, Weinberg GA, Iwnae MK, Blumkin AK, Edwards KM, et al. The Burden of Respiratory Syncytial Virus Infection in Young Children. New Engl J Med 360, 588-598 (2009).

2. Resch, B. Burden of respiratory syncytial virus infection in young children. World J Clin Pediatr 1, 8-12 (2012).

3. Nair H, Nokes DJ, Gessner BD, Dherani M, Madhi SA, Singleton RJ. Global burden of acute lower respiratory infections due to respiratory syncytial virus in young children: a systematic review and meta-analysis. Lancet 375, 1545-55 (2010).

4. Nokes DJ, Ngama M, Bett A, Abwao J, Munywoki P, English M, et al. Incidence and Severity of Respiratory Syncytial Virus Pneumonia in Rural Kenyan Children Identified through Hospital Surveillance. Clin Infect Dis 49, 1341-1349 (2009).

5. Yamin D, Jones FK, DeVincenzo JP, Gertler S, Kobiler, Townsend JP, et al. Vaccination strategies against respiratory syncytial virus. Proc Natl Acad Sci USA. 113, 13239-13244 (2016).

6. Saso, A. \& Kampmann, B. Vaccination against respiratory syncytial virus in pregnancy: a suitable tool to combat global infant morbidity and mortality? Lancet Infect Dis 16, e153-e163 (2016).

7. Poehling KA, Szilagyi PG, Staat MA, et al. Impact of maternal immunization on influenza hospitalizations in infants. Am J Obstet Gynecol. 2011;204(6 Suppl 1):S141-8.

8. Amirthalingam G, Andrews N, Campbell H, et al. Effectiveness of maternal pertussis vaccination in England: an observational study. Lancet. 2014;384(9953):1521-1528.

9. Zaman K, Roy E, Arifeen SE, et al. Effectiveness of maternal influenza immunization in mothers and infants. New Engl J Med. 2008;359(15):1555-64.

10. Madhi SA, Cutland CL, Kuwanda L, et al. Influenza Vaccination of Pregnant Women and Protection of Their Infants. New Engl J Med. 2014;371(10):918-931.

11. Jones CE, Calvert A, Le Doare K. Vaccination in Pregnancy - Recent Developments. The Pediatric Infectious Disease Journal (2018). doi:10.1097/INF.0000000000001822

12. Munoz FM, Piedra PA, Glezen WP. Safety and immunogenicity of respiratory syncytial virus purified fusion protein-2 vaccine in pregnant women. Vaccine 21, 3465-7 (2003).

13. Chu HY, Steinhoff MC, Magaret A, Zaman K, Roy E, Langdon G, et al. Respiratory Syncytial Virus Transplacental Antibody Transfer and Kinetics in Mother-Infant Pairs in Bangladesh. J Infect Dis 210, 1582-1589 (2014).

14. Kaaijk P, Luytjes W, Rots N. Vaccination against RSV: is maternal vaccination a good alternative to other approaches? Hum Vaccin immunother $\mathbf{9}$, 1263-7 (2013).

15. Bisset K, Paterson P. Strategies for increasing uptake of vaccination in pregnancy in high-income countries: A systematic review. Vaccine (2018). doi:10.1016/j.vaccine.2018.04.013

16. Blehar MC, Spong C, Grady C, Goldkind SF, Sahin L, Clayton JA. Enrolling pregnant women: issues in clinical research. Womens Health Issues 23, e39-45 (2013). 
17. Frew PM, Saint-Victor DS, Brewinski Isaacs M, Kim S, Swamy GK, Sheffield JS. Recruitment and retention of pregnant women into clinical research trials: an overview of challenges, facilitators, and best practices. Clin Infect Dis. 59 Suppl 7, S400-7 (2014).

18. NHS Digital. NHS Maternity Statistics, England 2016-2017. (2018).

19. Donaldson B, Jain P, Holder BS, Lindsey B, Regan L, Kampmann B. What determines uptake of pertussis vaccine in pregnancy? A cross sectional survey in an ethnically diverse population of pregnant women in London. Vaccine 33, 5822-5828 (2015).

20. Panda B, Stiller R, Panda, A. Influenza vaccination during pregnancy and factors for lacking compliance with current CDC guidelines. J Matern Fetal Neonatal Med 24, 402-406 (2011).

21. Goldfarb IT, Little S, Brown J, Riley LE. Use of the combined tetanusdiphtheria and pertussis vaccine during pregnancy. A J Obstet Gynecol 211, 299.e1-299.e5 (2014).

22. McQuaid F, Jones C, Steven Z, Meddaugh G, O'Sullivan C, Donaldson B, et al. Antenatal vaccination against Group B streptococcus: Attitudes of pregnant women and healthcare professionals in the UK to participation in clinical trials and routine implementation. Acta Obstet Gynecol Scand 97, 330-340(2018).

23. Dempsey A, Brewer S, Sevick C, et al. Tdap vaccine attitudes and utilization among pregnant women from a high-risk population. Hum Vaccin Immunother 12, 872-878 (2016).

24. Wiley KE, Massey PD, Cooper SC, Wood NJ, Ho J, et al. Uptake of influenza vaccine by pregnant women: a cross-sectional survey. Med J Aust 198, 373-375 (2013).

25. Wiley KE, Massey PD, Cooper SC, Wood NJ, Quinn HE, Leask J. Pregnant women's intention to take up a post-partum pertussis vaccine, and their willingness to take up the vaccine while pregnant: A cross sectional survey. Vaccine 31, 3972-3978 (2013).

26. Mitchell $\mathrm{K}$, Baillie L, Phillips N. Increasing nurse and midwife engagement in research activity. Nursing Standard 29, 37-42 (2015).

27. Purkis J, Jackson JA, Hundt G, Stockman C. Increasing nursing research capacity in the workplace. Nurs Times 104, 28-31 (2008).

28. Sim J, Ulanika A, Katikireddi S, Gorman D. 'Out of two bad choices, I took the slightly better one': Vaccination dilemmas for Scottish and Polish migrant women during the H1N1 influenza pandemic. Public Health 125, 505-511 (2011).

29. Marsh H, Malik F, Shapiro E, Omer S, Frew P. Message Framing Strategies to Increase Influenza Immunization Uptake Among Pregnant African American Women. Matern Child Health J 18, 1639-1647 (2014).

30. Zhou L, Zhang D, Yang C, Wang Y. Harnessing social media for health information management. Electron Commer R A 27, (2018).

31. Gazmararian JA, Elon L, Yang B, Graham M, Parker R. Text4baby program: an opportunity to reach underserved pregnant and postpartum women? Matern Child Health J 18, 223-32 (2014).

32. Holder B, Borqeau M, Donaldson B, Davies J, Kampmann B. MatImms: A smartphone app to inform and educate women about maternal immunisation. Poster presentation at 4th International Neonatal and Maternal Immunisation Symposium, Brussels, Belgium, 10-12/09/2017 
33. Coleman-Phox K, Laraia BA, Adler N, Vieten C, Thomas M, Epel E. Recruitment and retention of pregnant women for a behavioral intervention: lessons from the maternal adiposity, metabolism, and stress (MAMAS) study. Prev Chronic Dis 10, (2013).

34. Kerver JM, Elliot MR, Norman GS, Sokol RJ, Keating DP, Copeland GE, et al. Pregnancy recruitment for population research: the National Children's Study vanguard experience in Wayne County, Michigan. Paediatr Perinat Epidemiol 27, 303-11 (2013).

35. Shere M, Zhao AY, Koren G. The role of social media in recruiting for clinical trials in pregnancy. PLoS ONE 9, e92744 (2014).

36. Webb H, Street J, Marshall H. Incorporating immunizations into routine obstetric care to facilitate Health Care Practitioners in implementing maternal immunization recommendations. Hum Vaccin Immunother 10, 1114-21 (2014). 37. Krishnaswamy S, Wallace E, Buttery J Giles M. Strategies to implement maternal vaccination: A comparison between standing orders for midwife delivery, a hospital based maternal immunisation service and primary care. Vaccine 36, 1796-1800 (2018). 
Table 1: Characteristics of the questionnaire respondents (pregnant women and maternity healthcare professionals)

\begin{tabular}{|c|c|c|}
\hline Characteristic & $\begin{array}{l}\text { Pregnant women, } \\
n=314\end{array}$ & $\begin{array}{l}\text { Healthcare professionals, } \\
\mathrm{n}=199\end{array}$ \\
\hline \multicolumn{3}{|r|}{ 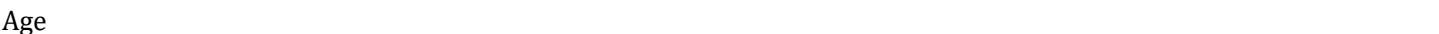 } \\
\hline $16-24$ & $34(11 \%)$ & \\
\hline $25-30$ & $107(34 \%)$ & \\
\hline $31-35$ & $92(29 \%)$ & \\
\hline $36-40$ & $58(19 \%)$ & \\
\hline $41+$ & $13(4 \%)$ & \\
\hline \multicolumn{3}{|l|}{ Gestation (weeks) } \\
\hline$<12$ & $8(2 \%)$ & \\
\hline $12-16$ & $37(12 \%)$ & \\
\hline $17-20$ & $31(10 \%)$ & \\
\hline $21-30$ & $55(18 \%)$ & \\
\hline $31-36$ & $93(30 \%)$ & \\
\hline$>37$ & $76(24 \%)$ & \\
\hline \multicolumn{3}{|l|}{ Study site } \\
\hline A & $88(28 \%)$ & $43(22 \%)$ \\
\hline B & $77(25 \%)$ & $53(27 \%)$ \\
\hline $\mathrm{C}$ & $79(25 \%)$ & $61(31 \%)$ \\
\hline $\mathrm{D}$ & $70(22 \%)$ & $42(21 \%)$ \\
\hline \multicolumn{3}{|l|}{ Ethnicity } \\
\hline $\begin{array}{l}\text { Asian (British, Indian, Pakistani, Bangladeshi, Chinese, } \\
\text { other) }\end{array}$ & $25(8 \%)$ & $4(2 \%)$ \\
\hline Black (British, African, Caribbean, other) & $17(5 \%)$ & $4(2 \%)$ \\
\hline White (British, Irish, other) & $248(79 \%)$ & $175(88 \%)$ \\
\hline Mixed (Caribbean, African, Asian, other) & $11(4 \%)$ & $6(3 \%)$ \\
\hline Other ethnic group (Arab, other) & $3(1 \%)$ & $0(0 \%)$ \\
\hline Did not want to say & $1(0.3 \%)$ & $1(1 \%)$ \\
\hline No response & $10(3 \%)$ & $9(5 \%)$ \\
\hline \multicolumn{3}{|l|}{ Has children } \\
\hline No & $142(45 \%)$ & $72(36 \%)$ \\
\hline Yes & $172(55 \%)$ & $127(64 \%)$ \\
\hline \multicolumn{3}{|l|}{ Profession } \\
\hline Obstetrics & & $37(19 \%)$ \\
\hline Midwifery & & $151(76 \%)$ \\
\hline No response & & $11(6 \%)$ \\
\hline \multicolumn{3}{|l|}{ Midwifery seniority } \\
\hline Band 5 (newly-qualified midwife) & & $8(5 \%)$ \\
\hline Band 6 (junior midwife) & & $84(56 \%)$ \\
\hline Band 7 (senior midwife) & & $46(30 \%)$ \\
\hline Band 8 (midwifery manager) & & $8(5 \%)$ \\
\hline No response & & $5(3 \%)$ \\
\hline \multicolumn{3}{|l|}{ Obstetrician seniority } \\
\hline Specialty training years 1-3 (or equivalent) & & $8(22 \%)$ \\
\hline Specialty training years 4-6 (or equivalent) & & $6(16 \%)$ \\
\hline Specialty training years 7-8 (or equivalent) & & $6(16 \%)$ \\
\hline Consultant & & $17(46 \%)$ \\
\hline \multicolumn{3}{|l|}{ Time spent working in maternity care (years) } \\
\hline$<2$ & & $17(9 \%)$ \\
\hline $2-5$ & & $29(15 \%)$ \\
\hline $6-10$ & & $37(19 \%)$ \\
\hline $11-15$ & & $20(10 \%)$ \\
\hline $16-20$ & & $26(13 \%)$ \\
\hline$>21$ & & $62(31 \%)$ \\
\hline No response & & $8(4 \%)$ \\
\hline
\end{tabular}


Table 2: Ordinal regression analysis of factors predicting pregnant women's willingness to consider undergoing RSV vaccination during pregnancy as part of a clinical trial, or if routinely recommended

\begin{tabular}{|c|c|c|c|c|}
\hline Variable & $\begin{array}{l}\text { Number who'd be } \\
\text { 'extremely likely' or } \\
\text { 'likely' to accept RSV } \\
\text { vaccination as part of } \\
\text { a clinical trial }\end{array}$ & $\begin{array}{l}\text { Adjusted odds ratio } \\
(95 \% \text { CI })\end{array}$ & $\begin{array}{l}\text { Number who'd be } \\
\text { extremely likely' or } \\
\text { 'likely' to accept RSV } \\
\text { vaccination if routinely } \\
\text { recommended }\end{array}$ & $\begin{array}{l}\text { Adjusted odds } \\
\text { ratio }(95 \% \mathrm{CI})\end{array}$ \\
\hline \multicolumn{5}{|l|}{ Age in years } \\
\hline $16-24$ & $18 / 34(53 \%)$ & $1.42(1.72-9.86) * *$ & $27 / 34(79 \%)$ & $0.68(0.28-1.67)$ \\
\hline $25-35$ & $54 / 199(27 \%)$ & $1.18(0.67-2.07)$ & $149 / 198(75 \%)$ & $0.71(0.39-1.28)$ \\
\hline $36-45$ & $16 / 70(23 \%)$ & 1.00 for reference & $53 / 70(76 \%)$ & 1.00 for reference \\
\hline \multicolumn{5}{|l|}{ Gestation in weeks } \\
\hline$<12$ & $3 / 8(38 \%)$ & $1.99(0.46-8.51)$ & $6 / 8(75 \%)$ & $0.67(0.15-3.00)$ \\
\hline $12-20$ & $24 / 68(35 \%)$ & $1.26(0.72-2.22)$ & $52 / 68(76 \%)$ & $1.17(0.65-2.10)$ \\
\hline $21-30$ & $18 / 55(33 \%)$ & $2.29(1.22-4.31) * *$ & $42 / 54(78 \%)$ & $2.10(1.07-4.13) *$ \\
\hline $31+$ & $43 / 168(26 \%)$ & 1.00 for reference & $128 / 168(76 \%)$ & 1.00 for reference \\
\hline \multicolumn{5}{|l|}{ Study site } \\
\hline Site A & $25 / 86(29 \%)$ & $0.80(0.40-1.59)$ & $65 / 87(75 \%)$ & $0.99(0.49-2.00)$ \\
\hline Site $B$ & $23 / 77(30 \%)$ & $0.72(0.35-1.49)$ & $62 / 76(82 \%)$ & $1.26(0.59-2.69)$ \\
\hline Site $C$ & $20 / 79(25 \%)$ & $0.54(0.26-1.10)$ & $55 / 76(72 \%)$ & $0.78(0.37-1.63)$ \\
\hline Site D & $20 / 70(29 \%)$ & 1.00 for reference & $50 / 69(72 \%)$ & 1.00 for reference \\
\hline \multicolumn{5}{|l|}{ Previous children } \\
\hline Yes & $50 / 171(29 \%)$ & $1.13(0.71-1.81)$ & $122 / 171(71 \%)$ & $0.64(0.39-1.05)$ \\
\hline No & $39 / 141(28 \%)$ & 1.00 for reference & 110/137 (80\%) & 1.00 for reference \\
\hline \multicolumn{5}{|l|}{ Ethnicity } \\
\hline White British & $66 / 224(29 \%)$ & $1.27(0.73-2.21)$ & $177 / 223(79 \%)$ & $2.16(1.22-3.83) * *$ \\
\hline Non-White British & $23 / 88(26 \%)$ & 1.00 for reference & $55 / 85(65 \%)$ & 1.00 for reference \\
\hline \multicolumn{5}{|l|}{ Previous RSV experience } \\
\hline Direct experience & $5 / 8(63 \%)$ & $9.07(1.62-50.86) *$ & $8 / 8(100 \%)$ & $8.20(0.71-94.16)$ \\
\hline Indirect experience & $5 / 13(38 \%)$ & $1.11(0.32-3.81)$ & $10 / 13(77 \%)$ & $1.09(0.30-3.96)$ \\
\hline No experience & $79 / 291(27 \%)$ & 1.00 for reference & $214 / 287(75 \%)$ & 1.00 for reference \\
\hline \multicolumn{5}{|l|}{$R S V$ familiarity } \\
\hline Good/some understanding & $5 / 14(36 \%)$ & $0.54(0.12-2.30)$ & $11 / 14(79 \%)$ & $1.77(0.37-8.56)$ \\
\hline Poor understanding & $21 / 77(27 \%)$ & $0.80(0.47-1.38)$ & $55 / 76(72 \%)$ & $0.96(0.55-1.68)$ \\
\hline No understanding & $63 / 219(29 \%)$ & 1.00 for reference & $164 / 216(76 \%)$ & 1.00 for reference \\
\hline \multicolumn{5}{|l|}{ Perceived RSV frequency } \\
\hline Extremely/moderately common & $18 / 50(36 \%)$ & $1.12(0.53-2.35)$ & $39 / 51(76 \%)$ & $1.03(0.47-2.23)$ \\
\hline Somewhat common & $34 / 99(34 \%)$ & $1.52(0.88-2.61)$ & $75 / 98(77 \%)$ & $0.93(0.53-1.64)$ \\
\hline Slightly/not at all common & $37 / 143(26 \%)$ & 1.00 for reference & $107 / 141(76 \%)$ & 1.00 for reference \\
\hline \multicolumn{5}{|l|}{ Perceived RSV severity } \\
\hline Extremely/moderately serious & $43 / 129(33 \%)$ & $1.22(0.58-2.57)$ & $100 / 129(78 \%)$ & $1.31(0.60-2.86)$ \\
\hline Somewhat serious & $33 / 117(28 \%)$ & $0.93(0.47-1.84)$ & $87 / 115(76 \%)$ & $1.06(0.52-2.18)$ \\
\hline Slightly/not at all serious & $13 / 43(30 \%)$ & 1.00 for reference & $33 / 43(77 \%)$ & 1.00 for reference \\
\hline \multicolumn{5}{|c|}{ Bronchiolitis familiarity and experience } \\
\hline $\begin{array}{l}\text { Good/moderate understanding and } \\
\text { direct/indirect experience }\end{array}$ & $27 / 88(31 \%)$ & $1.30(0.65-2.60)$ & $68 / 89(76 \%)$ & $0.75(0.36-1.53)$ \\
\hline Slight understanding & $29 / 102(28 \%)$ & $1.13(0.63-2.00)$ & $77 / 101(76 \%)$ & $0.81(0.44-1.48)$ \\
\hline No understanding & $32 / 120(27 \%)$ & 1.00 for reference & $86 / 116(74 \%)$ & 1.00 for reference \\
\hline \multicolumn{5}{|l|}{ Perceived bronchiolitis frequency } \\
\hline Extremely/moderately common & $33 / 107(31 \%)$ & $0.67(0.33-1.37)$ & $85 / 107(79 \%)$ & $1.04(0.49-2.19)$ \\
\hline Somewhat common & $26 / 96(27 \%)$ & $1.25(0.68-2.31)$ & $69 / 95(73 \%)$ & $1.36(0.72-2.60)$ \\
\hline Slightly/not at all common & $26 / 101(26 \%)$ & 1.00 for reference & $73 / 98(74 \%)$ & 1.00 for reference \\
\hline \multicolumn{5}{|l|}{ Perceived bronchiolitis severity } \\
\hline Extremely/moderately serious & $55 / 190(29 \%)$ & $0.38(0.15-0.93) *$ & $143 / 188(76 \%)$ & $0.63(0.24-1.65)$ \\
\hline Somewhat serious & $19 / 84(23 \%)$ & $0.27(0.11-0.68) *$ & $62 / 84(74 \%)$ & $0.52(0.20-1.36)$ \\
\hline Slightly/not at all serious & $11 / 28(39 \%)$ & 1.00 for reference & $20 / 26(77 \%)$ & 1.00 for reference \\
\hline
\end{tabular}

$$
*=\mathrm{p}<0.05 ; * *=\mathrm{p}<0.01
$$


Table 3: Ordinal regression analysis of factors predicting the willingness of healthcare professionals to support RSV vaccination during pregnancy as part of a clinical trial, or if routinely recommended

\begin{tabular}{|c|c|c|c|c|}
\hline Variable & $\begin{array}{l}\text { Number who'd be } \\
\text { 'very likely' or } \\
\text { 'likely' to support } \\
\text { RSV vaccination as } \\
\text { part of a clinical } \\
\text { trial }\end{array}$ & $\begin{array}{l}\text { Adjusted odds ratio } \\
(95 \% \mathrm{CI})\end{array}$ & $\begin{array}{l}\text { Number who'd be } \\
\text { 'very likely' or } \\
\text { 'likely' to support } \\
\text { RSV vaccination if } \\
\text { routinely } \\
\text { recommended }\end{array}$ & $\begin{array}{l}\text { Adjusted odds } \\
\text { ratio }(95 \% \mathrm{CI})\end{array}$ \\
\hline \multicolumn{5}{|l|}{ Professional group } \\
\hline Obstetrics & $34 / 37(92 \%)$ & $2.50(1.01-6.16) *$ & $33 / 37$ (89\%) & $4.08(1.53-9.81)^{* *}$ \\
\hline Midwifery & $102 / 151(68 \%)$ & 1.00 for reference & $119 / 151(79 \%)$ & 1.00 for reference \\
\hline \multicolumn{5}{|l|}{ Time in maternity care } \\
\hline $21+$ years & $46 / 62(74 \%)$ & $0.51(0.14-1.83)$ & $46 / 62(74 \%)$ & $0.43(0.12-1.62)$ \\
\hline 11-20 years & $31 / 46(67 \%)$ & $0.38(0.11-1.34)$ & $34 / 46(74 \%)$ & $0.79(0.22-2.86)$ \\
\hline 2-10 years & $47 / 66(71 \%)$ & $0.68(0.22-2.10)$ & $60 / 66(91 \%)$ & $1.39(0.43-4.42)$ \\
\hline$<2$ years & $14 / 17(82 \%)$ & 1.00 for reference & $15 / 17(88 \%)$ & 1.00 for reference \\
\hline \multicolumn{5}{|l|}{ Study site } \\
\hline Site A & $30 / 41(73 \%)$ & $3.94(1.46-10.61) * *$ & $34 / 41(83 \%)$ & $3.95(1.39-11.26)$ * \\
\hline Site $B$ & $35 / 53(66 \%)$ & $3.19(1.23-8.30) *$ & $46 / 53(87 \%)$ & $\begin{array}{l}6.23(2.22-17.46) \\
* * *\end{array}$ \\
\hline Site $C$ & $51 / 61(84 \%)$ & $5.80(2.36-14.21)^{* * *}$ & $47 / 61(77 \%)$ & $1.97(0.81-4.83)$ \\
\hline Site D & $22 / 37(59 \%)$ & 1.00 for reference & $29 / 37(78 \%)$ & 1.00 for reference \\
\hline \multicolumn{5}{|l|}{ Has own children } \\
\hline Yes & $88 / 127(69 \%)$ & $0.59(0.28-1.24)$ & $101 / 127(80 \%)$ & $0.86(0.39-1.91)$ \\
\hline No & $50 / 65(77 \%)$ & 1.00 for reference & $55 / 65(85 \%)$ & 1.00 for reference \\
\hline \multicolumn{5}{|l|}{ Ethnicity } \\
\hline White British & $126 / 175(72 \%)$ & $1.01(0.34-3.06)$ & $142 / 175(81 \%)$ & $1.41(0.44-4.46)$ \\
\hline Non-White British & $12 / 17(71 \%)$ & 1.00 for reference & $14 / 17(82 \%)$ & 1.00 for reference \\
\hline \multicolumn{5}{|l|}{ RSV experience } \\
\hline Direct experience & $22 / 26(85 \%)$ & $2.65(0.79-8.86)$ & $24 / 26(92 \%)$ & $1.41(0.39-5.07)$ \\
\hline Indirect experience & $20 / 27(74 \%)$ & $1.17(0.42-3.31)$ & $23 / 27(85 \%)$ & $0.74(0.25-2.22)$ \\
\hline No experience & $96 / 139(69 \%)$ & 1.00 for reference & $109 / 139(78 \%)$ & 1.00 for reference \\
\hline \multicolumn{5}{|l|}{ RSV familiarity } \\
\hline Good/some understanding & $19 / 22(86 \%)$ & $4.42(1.10-17.83) *$ & $20 / 22(91 \%)$ & $6.07(1.23-29.93) *$ \\
\hline Poor understanding & $87 / 114(76 \%)$ & $1.81(0.88-3.73)$ & $91 / 114(80 \%)$ & $1.07(0.51-2.24)$ \\
\hline No understanding & $32 / 55(58 \%)$ & 1.00 for reference & $44 / 55(80 \%)$ & 1.00 for reference \\
\hline \multicolumn{5}{|l|}{ Perceived RSV frequency } \\
\hline Extremely common & $29 / 36(81 \%)$ & $1.43(0.45-4.51)$ & $30 / 36(83 \%)$ & $1.96(0.57-6.76)$ \\
\hline Moderately/somewhat common & $84 / 116(72 \%)$ & $0.92(0.43-1.98)$ & $95 / 116(82 \%)$ & $1.20(0.54-2.67)$ \\
\hline Slightly/not at all common & $25 / 39(64 \%)$ & 1.00 for reference & $30 / 39(77 \%)$ & 1.00 for reference \\
\hline \multicolumn{5}{|l|}{ Perceived RSV severity } \\
\hline Extremely serious & $27 / 35(77 \%)$ & $4.85(1.11-21.28) *$ & $26 / 35(74 \%)$ & $1.25(0.28-5.55)$ \\
\hline Moderately/somewhat serious & $113 / 138(82 \%)$ & $4.16(1.26-13.75) *$ & $117 / 138(85 \%)$ & $4.41(1.32-14.78) *$ \\
\hline \multicolumn{5}{|l|}{$\begin{array}{l}\text { Bronchiolitis familiarity and } \\
\text { experience }\end{array}$} \\
\hline $\begin{array}{l}\text { Good/moderate understanding and } \\
\text { indirect/direct experience }\end{array}$ & $58 / 77(75 \%)$ & $0.84(0.10-6.94)$ & $66 / 77(86 \%)$ & $0.99(0.12-8.35)$ \\
\hline Slight understanding & $78 / 111(70 \%)$ & $0.98(0.13-7.49)$ & $87 / 111(78 \%)$ & $0.98(0.13-7.56)$ \\
\hline No understanding & $2 / 4(50 \%)$ & 1.00 for reference & $3 / 4(75 \%)$ & 1.00 for reference \\
\hline \multicolumn{5}{|l|}{ Perceived bronchiolitis frequency } \\
\hline Extremely common & $29 / 34(85 \%)$ & $1.05(0.34-3.25)$ & $27 / 34(79 \%)$ & $0.55(0.17-1.80)$ \\
\hline Moderately/somewhat common & $88 / 124(71 \%)$ & $1.44(0.63-3.29)$ & $104 / 124(84 \%)$ & $1.07(0.45-2.51)$ \\
\hline Slightly/not at all common & $21 / 34(62 \%)$ & 1.00 for reference & $25 / 34(74 \%)$ & 1.00 for reference \\
\hline \multicolumn{5}{|l|}{ Perceived bronchiolitis severity } \\
\hline Extremely serious & $36 / 47(77 \%)$ & $0.35(0.054-2.28)$ & $38 / 47(81 \%)$ & $0.96(0.15-6.39)$ \\
\hline Moderately/somewhat serious & $96 / 136(71 \%)$ & $0.29(0.052-1.65)$ & $111 / 136(82 \%)$ & $0.54(0.10-2.99)$ \\
\hline Slightly/not at all serious & $6 / 9(67 \%)$ & 1.00 for reference & $7 / 9(78 \%)$ & 1.00 for reference \\
\hline
\end{tabular}

$*=\mathrm{p}<0.05 ; * *=\mathrm{p}<0.01 ; * * *=\mathrm{p}<0.001$ 


\section{Supplementary information}

\section{1) Questions for pregnant women analysed in this study}

(1) Before taking part in this survey, how familiar were you with Respiratory Syncytial Virus (sometimes shortened to RSV)?

$\square$ I have never heard of it

$\square \mathrm{I}$ have heard of it, but don't really know what it is

$\square$ I know some facts about what it is

$\square$ I have a good understanding about RSV infection and its implications

(2) What experience do you have of RSV?

$\square$ I have no experience of it

$\square \mathrm{I}$ know someone who has experience of it

$\square$ I have direct experience of it

(3) How common do you think RSV infection is in babies and young children?

$\square$ Not at all common

$\square$ Slightly common

$\square$ Somewhat common

$\square$ Moderately common

$\square$ Extremely common

(4) How serious do you think RSV infection is for babies and young children?

$\square$ Not at all serious

$\square$ Slightly serious

$\square$ Somewhat serious

$\square$ Moderately serious

$\square$ Extremely serious

(5) Before taking part in this survey, how familiar were you with bronchiolitis in babies and young children?

$\square$ I have never heard of it

$\square$ I have heard of it but don't know what it is

$\square$ I know some facts about it

$\square$ I know what it is and know someone who has experience of it

$\square \mathrm{I}$ know what it is and have direct experience of it

(6) How common do you think bronchiolitis is in babies and young children?

$\square$ Not at all common

$\square$ Slightly common

$\square$ Somewhat common

$\square$ Moderately common 
(7) How serious do you think bronchiolitis is for babies and young children?

$\square$ Not at all serious

$\square$ Slightly serious

$\square$ Somewhat serious

$\square$ Moderately serious

$\square$ Extremely serious

(8) Would you be potentially willing to receive a RSV vaccine during pregnancy as part of a research study to determine its safety and effectiveness, before the vaccine is approved for routine use?

Your response to this question will not affect whether or not you receive further information about such studies and does not mean that you are agreeing to take part in any vaccine research studies.

$\square$ Extremely unlikely

$\square$ Unlikely

$\square$ Neutral/not sure

$\square$ Likely

$\square$ Extremely likely

(9) What information would you consider to be important when considering taking part in a research study of a RSV vaccine?

Please rank the top 3 most important to you: (1= most important information for you to know)

$\square$ How common RSV is

$\square$ How serious RSV is

$\square$ Number of healthy adults who have received the vaccine

$\square$ Number of pregnant women who have received the vaccine

$\square$ Likelihood of side effects for me

$\square$ Likelihood of side effects for my baby

(10) One type of a research study is a "Randomised Controlled Trial" where there are two (or more) groups who are treated exactly the same, except only one group gets the true vaccine under investigation. The other group may get a 'placebo' (dummy or inactive) injection.

This type of study allows the researchers to check that any differences between the groups are due to the vaccine only. Importantly, patients or staff do not get to choose whether they receive the proper vaccine or the dummy.

\section{After reading the above information:}

$\square$ I would be less likely to take part as I would want to guarantee that I would have the vaccine

$\square$ I would be more likely to take part as I might not get the vaccine

$\square$ This would not affect my decision 
(11) In some randomised controlled trials, patients are given different doses (amounts) of the vaccine under investigation in order to work out which is the best dose to use in future vaccines. These different doses would be calculated before the trial starts, but patients or staff involved in the study do not get to choose which of these doses they receive.

After reading the above information:

$\square$ I would be less likely to take part

$\square$ I would be more likely to take part

$\square$ This would not affect my decision

(12) What other factors would discourage you from taking part in a research study of a vaccine in pregnancy?

Please rank the following: (1=factor that would most discourage you, $4=$ factor least likely to discourage you)

$\square$ Number of hospital visits

$\square$ Number of home visits

$\square$ Number of blood tests for me

$\square$ Number of blood tests for baby

$\square$ Other, please

specify

$\cdots$

(13) How would you most like to be approached about taking part in a research study?

Tick one answer:

$\square$ Asked by my midwife

Asked by my obstetrician

$\square$ Asked by my GP

$\square$ Given a leaflet/poster with contact details for the study team

$\square$ Adverts of the internet (e.g. pregnancy forums)

$\square$ Email from the study team

$\square$ Approached directly by the study midwife/doctor

$\square$ I wouldn’t mind how I was approached

Other:

(14) If you were approached about taking part in a research study, how much time would you like to fully consider whether or not you would like to take part?

$\square<24$ hours

$\square$ 1-2 days

$\square$ 3-7 days

$\square$ 2-3 weeks

$\square>1$ month

(15) Would you be willing to receive this vaccine in pregnancy if it was routinely recommended for use in pregnancy in the NHS?

$\square$ Definitely

$\square$ Probably

$\square$ Maybe 
$\square$ Probably not

$\square$ Definitely not

(16) There are a number of different vaccines that are being designed for use in pregnancy to protect mothers and infants against severe infection. How many vaccines would be acceptable to you in pregnancy?

$\square 0$

$\square 1$

$\square 2$

$\square 3$

$\square 4$

$\square 5$

$\square$ More than 5

(27) How old are you in years?

16-24 $\square$ 25-30 $\square$ 31-35 $\square$ 36-40 $\square$ 41-45 $\square$ 46+ $\square$

(28) How many weeks pregnant are you?

Less than $12 \square \quad 12-16 \square$ 17-20 $\square$ 21-30 $\square 31-36 \square 37+$

(19) To what ethnic group do you feel you belong? (Please circle)

White

British

- English / Welsh / Scottish / Northern Irish

/ British Irish

- Gypsy or Irish Traveller

specify).....

- Other (please specify)

Mixed/Multiple ethnic groups

- White and Black Caribbean

- White and Black African

specify).....

- White and Asian

- Other (please specify)

Asian / Asian British

- Indian

- Pakistani

- Bangladeshi

- Chinese

- Other (please specify)

(20) Have you had any children before?

$\square$ Yes.

If yes, how many?

What are their ages?

$$
\begin{aligned}
& \text { Child 1: Less than } 1 \square \quad 1-5 \square \quad 6-10 \square \quad 11-16 \square \quad 17+\square \\
& \text { Child 2: Less than } 1 \square \quad 1-5 \square \quad 6-10 \square \quad 11-16 \square \quad 17+\square \\
& \text { Child 3: Less than } 1 \square \quad \text { 1-5 } \square \quad 6-10 \square \quad 11-16 \square \quad 17+\square
\end{aligned}
$$

Black / African / Caribbean / Black

- African

- Caribbean

- Other (please

Other ethnic group

- Arab

- Other (please

I'd prefer not to say 
(21) Optional: Do you have any comments or concerns about any of the issues raised in the questionnaire?

\section{2) Questions for healthcare professionals analysed in this study}

(1) Before taking part in this survey, how familiar were you with Respiratory Syncytial Virus (sometimes shortened to RSV)?

$\square$ I have never heard of it

$\square$ I have heard of it, but don't really know what it is

$\square \mathrm{I}$ know some facts about what it is

$\square$ I have a good understanding about RSV infection and its implications

(2) What experience do you have of RSV?

$\square$ I have no experience of it

$\square$ I know someone who has experience of it

$\square$ I have direct experience of it

(3) How common do you think RSV infection is in young children?

$\square$ Not at all common

$\square$ Slightly common

$\square$ Somewhat common

$\square$ Moderately common

$\square$ Extremely common

(4) How serious do you think RSV infection is for young children?

$\square$ Not at all serious

$\square$ Slightly serious

$\square$ Somewhat serious

$\square$ Moderately serious

$\square$ Extremely serious

(5) Before taking part in this survey, how familiar were you with bronchiolitis in young children?

$\square$ I have never heard of it

$\square$ I have heard of it but don't know what it is

$\square$ I know some facts about it

$\square$ I know what it is and know someone who has experience of it

$\square \mathrm{I}$ know what it is and have direct experience of it

(6) How common do you think bronchiolitis is in young children?

$\square$ Not at all common

$\square$ Slightly common

$\square$ Somewhat common

$\square$ Moderately common 
$\square$ Extremely common

(7) How serious do you think bronchiolitis is for young children?

$\square$ Not at all serious

$\square$ Slightly serious

$\square$ Somewhat serious

$\square$ Moderately serious

$\square$ Extremely serious

(8) Would you be potentially willing to support a randomised controlled trial of RSV vaccine in pregnancy to determine its safety and how well it prevents infection in children, by signposting the study to women?

Your response to this question will not affect whether or not you receive further information about such studies

$\square$ Extremely unlikely

$\square$ Unlikely

$\square$ Neutral/not sure

$\square$ Likely

$\square$ Extremely likely

(9) Would you be willing to support the administration of this vaccine if it was routinely recommended for use in the NHS?

$\square$ Definitely

$\square$ Probably

$\square$ Maybe

$\square$ Probably not

$\square$ Definitely not

(10) What factors would influence your decision regarding whether or not you would be willing to support involvement in a RSV vaccine research study before it is licensed?

\section{Please rank the top 3 factors: $(1=$ factor that would most influence you)}

$\square$ The number of pregnant women who had previously received the vaccine in research studies

$\square$ How common RSV is in children

$\square$ Seriousness of RSV infection in young children

$\square$ How effective the vaccine is in preventing $R S V$ infection

$\square$ How effective the vaccine is in preventing severe RSV disease

$\square$ Risk of side effects for the mother

$\square$ Risk of side effects for developing baby

$\square$ Other (please specify):

(11) How many pregnant women would the vaccine have to be safely tested on in a research study for you to consider supporting such a trial?

$\square$ None 
$\square$ Over 10

$\square$ Over 100

$\square$ Over 500

$\square$ Over 1000

$\square$ Over 5000

$\square$ Over 10,000

$\square$ I would not support such a trial

(12) Which healthcare professional group do you belong to?

$\square$ Obstetrics

$\square$ Midwifery

$\square$ Other (please state)

(13) How long have you worked in maternity care?

$\square$ Under 2 years

$\square 2-5$ years

$\square 6-10$ years

$\square 11-15$ years

$\square 16-20$ years

$\square 21+$ years

(14) What is your grade?

1. Midwifery/nursing staff

Band $4 \square \quad$ Band $5 \square \quad$ Band 6 $\square \quad$ Band 7 $\square \quad$ Band $8 \square \quad$ Band 9

2. Obstetricians

ST 1-3 (or equivalent) $\square \quad$ ST 4-6 (or equivalent) $\square \quad$ ST 7-8 (or equivalent) $\square \quad$ Consultant $\square$

(15) Have you had any children before?

$\square$ Yes.

If yes, how many?.

What are their ages?

Child 1: Less than $1 \square \quad$ 1-5 $\square \quad 6-10 \square \quad 11-16 \square \quad 17+\square$
Child 2: Less than $1 \square \quad 1-5 \square \quad 6-10 \square \quad 11-16 \square \quad 17+\square$
Child 3: Less than $1 \square \quad$ 1-5 $\square \quad 6-10 \square \quad 11-16 \square \quad 17+\square$
Child 4: Less than $1 \square \quad$ 1-5 $\square \quad 6-10 \square \quad 11-16 \square \quad 17+\square$

$\square$ No

(16) To what ethnic group do you feel you belong? (Please circle)

White

British

- English / Welsh / Scottish / Northern Irish

/ British Irish

- Gypsy or Irish Traveller

specify)............................

- Other (please specify)
Black / African / Caribbean / Black

- African

- Caribbean

- Other (please 
Mixed/Multiple ethnic groups

- White and Black Caribbean

- White and Black African

specify)

- White and Asian

- Other (please specify)

Asian / Asian British

- Indian

- Pakistani

- Bangladeshi

- Chinese

- Other (please specify)
Other ethnic group

- Arab

- Other (please

(17) Optional: Do you have any comments or concerns about vaccination or vaccine research studies during pregnancy?

\section{3) Free-text comments from pregnant women and healthcare professionals}

Response to the question: Do you have any comments or concerns about vaccination or vaccine research studies during pregnancy?

\section{Pregnant women}

1. I think vaccine trials are very risky even though very important so every available information should be made available to the participant before commencing including all known possible side effects

2. Many vaccines contain unsafe levels of mercury in some cases some are produced on human tissue (DNA) and contain various other toxins. I believe a baby is born with a perfect immune system which takes up to 3 years to fully develop and that it's not healthy injecting a perfectly healthy child with chemicals and toxins (mercury)

3. I am glad to hear that the NICE guidelines will be reviewed and that possibly new vaccines will be introduced

4. I am taking part in a RSV vaccine trial

5. I'm very keen for my baby to have as many vaccines as possible \& fully support such research

6. I would want the vaccine fully tested and approved before I would have it

7. Our daughter suffered from bronchiolitis at age 2 weeks old so as long as the vaccine was safe we would definitely have it to prevent this baby suffering like our daughter did

8. I would consider vaccination if I was having a normal singleton pregnancy 
9. I'm a bit of a unique case because I've had an adverse reaction to a vaccine in the past and wouldn't risk it in pregnancy unless I had to

10. Child died at 20 months. RSV sounds very like what my son had when he died

11. No concerns. I am very pro vaccinations both for myself during pregnancy and for my children

12. I am having a slightly bumpy pregnancy and this is one of the reasons I would be reluctant to take part in a research study which could increase the risks for the pregnancy complications. If I was a low-risk person I would be more willing to take part. Likewise, if this wasn't my first baby I might be more willing

13. Information about the potential side effects of the trial vaccinations would have been helpful for me to make more informed decisions

14. I've not heard of RSV before sounds concerning and something I would have liked to have been told about earlier in my pregnancy

15. I've heard of many children developing chest infections as young babies and anything to avoid this I feel should be actively encouraged

16. I would like the opportunity to ask more questions and have more information before agreeing to vaccination

17. I would only have medication in pregnancy that has been approved by the BMA. Diabetics have a lot of complications anyway

18. No - thank you for all the amazing work/research you do

19. I believe the stage of drug trial to be more pertinent to the decision-making process than the number of vaccinations received.

20. My concern in taking part in a research study is the unknown side effects to my baby and whether the potential side effects would cause more harm than the virus itself. Whilst I appreciate research needs to be done and the vaccine will have been thoroughly tested on other test groups testing pregnant women/babies is still a concern for me

21. Not really aware enough of the issue to comment on some of the questions

22. In my experience, the flu vaccine has made me ill. I would not feel comfortable having a trial vaccine as a first-time mother

\section{Maternity healthcare professionals}

1. I would want to see safety data in non-pregnant participants concerning side effects and efficacy before I supported vaccine studies on pregnant women. I understand that effectiveness in preventing baby bronchiolitis could not be assessed using non-pregnant subjects but would reassure health workers that we aren't supporting an action that could cause harm.

2. I would worry about safety /side effects to mum and baby if not tested before being given to pregnant women

3. Knowledge to midwives about RSV is very limited without having first-hand experience of it or working alongside paediatric teams. It's not widely taught in training perhaps because our care for infants doesn't go much beyond 10-28 days postnatally 
4. My son needed ECMO because of this infection but he was too unstable to transfer to Gt O S we very nearly lost him at 12 days old. He caught it from his sister who was 2 and poorly when he was born. This serious infection wiped the first 2 months of a normal newborn period for us. He did get asthma as a child and took months to catch up.

5. Side effects - baby especially.

6. I'm not convinced that RS virus needs vaccination. Depends on the severity of chance of later disease in the child. I think we build up immunity ourselves and therefore the number needed to treat is probably high to prevent severe RS virus infection in children.

7. I would want some evidence that the vaccine is safe.

8. My children were born at $27 / 40$ and $32 / 40$ week's gestation. For our $27 / 40$ week-old baby it was very serious.

9. Potential risks to unborn and ability to be honest with mother about risks $v$ benefits.

10. Risk to unborn.

11. Can't really answer question of how many women vaccines would have to be safely tested on as I don't know what the predicted rate of adverse reactions/side effects. As long as sufficiently powered I would be happy. No concerns as long as properly conducted. Vaccination research environment is heavily regulated so very confident.

12. That the vaccine is safe for the mother and unborn child. This has to be paramount and is of high concern with the majority of the public.

13. When testing for side effects -there should be follow-up of at least 5 years on the child whose mother received the vaccine. We are woefully short on long-term effects and in order to fully discuss (and understand) the effects of vaccinations in pregnancy these time-frames should be mandatory. Lack of long-term data does not reassure me that we should be vaccinating in pregnancy.

14. Effect on the baby that are so far unknown. Another vaccine could it be combined with present vaccines?

15. I would worry about a trial re the long term unknown effects on the health of children whose mothers received the vaccine whilst they were in utero.

16. Yes, the potential risks to mother and unborn baby 